\title{
"BURNOUT" SYNDROME AMONG TEACHERS AND A MODEL FOR ITS DIAGNOSIS
}

\author{
Iv. Prokopov*, M. Legurska, V. Mircheva \\ Department of Information and In-service Training of Teachers, Sofia University "St. Kliment \\ Ohridski”, Sofia, Bulgaria
}

\begin{abstract}
The present study explains the cause of "burnout" among teachers and offers the author's model for its diagnosis.

Burnout syndrome can easily be called a "modern teacher's disease" due to the fact that it mainly affects the professional group of teachers.

In the present study we aim to present a brief analysis of the problem and to offer a methodology for diagnosing and self-diagnosing "burnout" among teachers.

The relevance of the research is related to the teachers high workload of and the problem of the aging teachers, who often complain of exhaustion, lack of motivation, unwillingness to work. This raises the question of the specific working conditions that lead to diseases of the professional group of teachers. For this reason it is necessary to periodically take measures for the prevention of "burnout" syndrome.
\end{abstract}

Key words: education system, educators, stress, health

\section{INTRODUCTION}

Burnout is a syndrome associated with professional activities and is characterized by depersonalization, emotional exhaustion and low personal achievements, which lead to both personal and professional negative consequences.

In the International Classification of Diseases, published by the World Health Organization in May 2019, burnout is recognized as an "occupational" phenomenon (1).

In the European Union, stress at work is the second most common health problem after diseases of the musculoskeletal system (2).

Poorly organized work, overload with activities (often considered meaningless), lack of diversity, boredom can have a negative impact on employees and cause permanent damage to their health.

\footnotetext{
*Correspondence to: Ivaylo Prokopov, Sofia University "St. Kliment Ohridski", Department of Information and In-service Training of Teachers, 1619, Sofia; 224, Tsar Boris III Blvd., Phone: +359888818941,e-mail: iprokopov@gmail.com
}

Workload or lack of it can be an important prerequisite for the emergence of stress, monotony and fatigue, which in the future will become a major factor in the emergence of the syndrome of burnout (3).

Burnout syndrome among staff was described in the 1974s by the American psychotherapist Herbert Freudenberger in his article "Staff burnout" The author observed and described an increased incidence of symptoms of emotional exhaustion and social isolation, as well as physical symptoms in people engaged in social activities (4). This term defines a state of exhaustion and frustration, a complex of symptoms and behavior problems accumulated as a result of prolonged stress at work. It explains the process of deterioration of the physical and mental condition of employees in educational institutions, who after several years of work become depressed, emotionally exhausted, nervous and irritable, cynical and suspicious of the people they work with (4-6).

Often affected by burnout syndrome are people with high altruistic ideals and requirements, as well as those with a strong sense of responsibility. 
The main feature of this syndrome is the increased feeling of intellectual, emotional and physiological exhaustion. It is seen as a professional phenomenon that affects all aspects of personality - physiological, emotional, behavioral, health. An increasing range of professions are influenced by the syndrome in the modern world - police officers, teachers, journalists, doctors and scientists. The occupational exhaustion syndrome is not a phenomenon that affects only a specific type of employees with a specific professional orientation. This is a global phenomenon that can affect any worker. The constantly increasing professional requirements of modern society with its intensive communications and modern technologies lead to greatly reduced physical activity, at the expense of increased psychosocial stress on the working person.

There are several theories in the specialized literature, describing a different number of stages in the process. Regardless of the number of phases, the described features are quite similar in content. Their presentation is useful because they would serve as guidelines for diagnosis and self-diagnosis, as well as to take measures to stop further development. According to Greenberg, this is a five-step progressive process with the following stages:

1. "Honeymoon" - a person starts work with enthusiasm and high expectations and puts a lot of energy and desire in it.

2. Stagnation - the appearance of the first signs of fatigue, apathy, "lack of fuel". In highly motivated people, these signs may not be manifested externally, as they will mobilize their internal resources and continue to be perfectionists. Less motivated people show visible signs of loss of interest in work, less energy, more frequent absences and violations of work discipline.

3. Chronic fatigue - is expressed both in physical signs (insomnia, frequent infectious and other diseases) and in psychological manifestations (irritability, depression, even anger ).

4. Crisis - a person clearly realizes that one`s expectations of the profession have not been realized, he has not been able to cope as he wanted in the beginning, and there is no strength and motivation to work "at full speed". Chronic diseases often develop, which further reduce work capacity and job satisfaction.
PROKOPOVIV., et al.

5. All problems take an acute form, and there is a real danger to the person's physical and mental health.

According to Greenberg, the development of the syndrome could be controlled at any stage. Also, the cycle can be repeated again and again. This makes especially important the issue of its timely recognition, as well as its distinction from other similar conditions stress, depression and others. Burnout is closely related to stress, but "it is not the result of stress per se, but of unresolved social stress." It can be described as the last stage at the end of a series of unsuccessful attempts to overcome prolonged and severe social stress associated with work. A number of studies show a complex relationship between it and job satisfaction. Depression may be one of the symptoms of burnout, but the syndrome is related to occupational activities and not to life problems at all (3).

The characteristics of burnout can be summarized by the following aspects:

$>\quad$ burnout is a phenomenon typical of professions with intensive interpersonal contacts and especially characteristic of the medical professions;

$>$ three dimensions are combined emotional exhaustion, depersonalization and self-presentation;

$>$ has a continuous development over time;

D has complex symptoms;

$>\quad$ there is a complex of risk factors for its development;

$>\quad$ leads to consequences on the whole person and one`s professional life;

$>\quad$ Burnout is between health and illness -

There is only one small step from the last stages of burnout to mental illness (7).

Burnout syndrome is often associated with mental illnesses such as depression, alcoholism, as well as chronic insomnia, increased risk of cardiovascular diseases, heart attack and permanent disability.

External factors for burnout (most often related to the workplace):

$>$ interpersonal extreme situations in professional everyday life

high position in the workplace and making responsible decisions 
$>\quad$ spending too much time at work combined with too much mental energy

$>$ extremely high requirements for achieving certain goals

$>\quad$ double workload for family and work reasons

Intra-personal prerequisites for burnout are:

$\begin{array}{ll}> & \text { High motivation } \\ > & \text { Strong commitment } \\ > & \text { focus } \\ > & \text { perfectionism } \\ > & \text { need for harmony } \\ & \text { idealism }(8)\end{array}$

Although burnout syndrome is associated primarily with negative effects on the individual and the organization, some experts draw attention to the possibilities for extracting some positives from it. They are found in several directions, united by the idea of a new beginning in personal growth, namely:

- to try to cope with the feeling of failure in the professional sphere (one of the signs of the syndrome);

- to rethink one's behavior and detect its ineffective manifestations;

- to re-evaluate a new hierarchy of their professional goals (taking into account their own resources);

- to seek support from others, which is a difficult step for many people;

- to look for opportunities for professional performance in other places, including a change of profession with all the resulting risks, etc.

The target group of teachers is the most numerous and is the basis of the educational system. A number of studies, as well as studies by the authors of this article, confirm that they are exposed to the daily effects of occupational stress and a large percentage of them show a strong emotional exhaustion, as an element of the burnout syndrome. The problem of coping with stress and the syndrome of professional exhaustion and its prevention are multifaceted. It requires analysis and solving a number of complex problems of an organizational, regulatory, qualification, behavioral, ethical and psychological nature.

Based on research, analysis, findings and established relationships, as well as from our own professional experience, we have developed a Model for complex research / diagnosis of burnout syndrome in teachers (Figure 1). We have relied on the developments of Sn. Yanakieva $(3,8)$ and other scientists $(9,10)$ for the prevention and management of stress in the medical professions.

Model for complex research / diagnosis of burnout syndrome in teachers/ includes:

$\checkmark \quad$ Psychological questionnaires for the Maslach Burnout Inventory (MBI), Gerald C. Greenberg test (11)

$\checkmark$ Questionnaires for personal characteristics - neuroticism, anxiety, extroversion, temperament, motivation, etc. (eg temperamental questionnaire - revised version (TCI-R)

$\checkmark \quad$ Workplace assessment cards

$\checkmark$ Questionnaires for measuring the psychological climate (Inductive measurement of psychological climate - IMPC, etc.)

$\checkmark$ Cards for assessment of individual factors - social status, age, gender, education

$\checkmark \quad$ Physiological tests - breathing, heart rate and pain

The model is divided into two parts:

Non-specialized tools:

- Questionnaires for personal characteristics (neuroticism, anxiety, extroversion, temperament, motivation, etc.)

- Cards for assessment of individual factors social status, age, gender, education

- Workplace assessment cards

- Questionnaires for measuring the psychological climate (IMPC, etc.)

- Physiological research

Specialized tools:

- Maslach Questionnaire (Maslach Burnout Inventory-MBI)

- Gerald S. Greenberg test

- Others

In the present study we present data from the survey on the socio-demographic profile of the surveyed people and the results of the questionnaire for burnout of K. Maslach.

The approbation of the overall model for burnout diagnostics will be performed after the restrictions due to Covid-19 are lifted. 


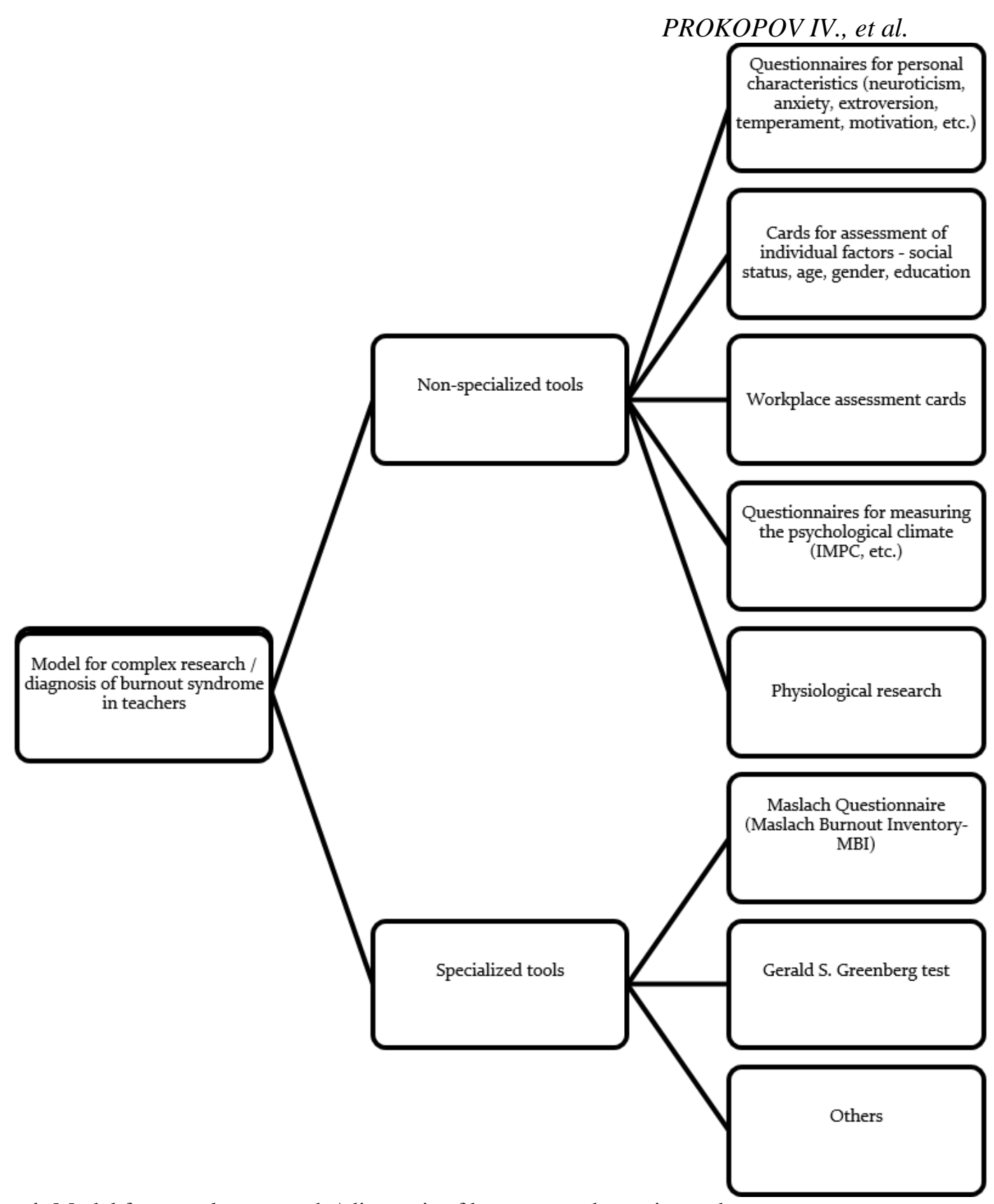

Figure 1. Model for complex research / diagnosis of burnout syndrome in teachers

\section{RESEARCH METHODOLOGY}

Toolkit - the survey is anonymous and includes:

- Questionnaire for burnout syndrome developed by Maslach and Jackson (Maslach Burnout Inventory - Human Services Survey).

- Questionnaire for the socio-demographic profile of the surveyed people.

Recognized as the leading measure of burnout, the Maslach Burnout Inventory ${ }^{\mathrm{TM}}$ (MBI) is validated by extensive research that has been conducted more than 35 years since its initial publication.

MBI-Human Services Survey (MBI-HSS): The MBI-HSS is the original and most widely used version of the MBI. Designed for professionals in the human services, it is appropriate for respondents working in a diverse array of occupations, including nurses, teachers, health and social workers.

\section{Measurement}

Burnout was measured using the emotional exhaustion (EE), depersonalization (DP) and personal accomplishment (PA) subscales that are parts of the 22-item MBI. The EE subscale describes feelings of being emotionally exhausted because of the work and contains nine items. The PA subscale contains eight items that describe beliefs of competence and successful achievement at work. The DP subscale describes detached and impersonal treatment of teachers and consists of five 
items. Each of the 22 items asks teachers to describe their feelings on a 7-point scale, ranging from never having those feelings to having those feelings a few times a week.

\section{SCORING RESULTS - INTERPRETATION}

Section A: Burnout (EE) emotional exhaustion Burnout (or depressive anxiety syndrome): Testifies to fatigue at the very idea of work, chronic fatigue, bad sleep, physical problems. For the MBI, as well as for most authors, "exhaustion would be the key component of the syndrome." Unlike depression, the problems disappear outside work.

- Total of 17 or less: Low-level of burnout

- Total between 18 and 29 inclusive: Moderate burnout

- Total over 30: High-level of burnout

Section B: Depersonalization

"Depersonalization" (or loss of empathy): Rather "dehumanization" in interpersonal relations.

The notion of detachment is excessive, leading to cynicism and negative attitudes with regard to patients or colleagues, feelings of guilt, avoidance of social contacts and withdrawing into oneself. The professional blocks the empathy he/she can show to his patients and/or colleagues.

- Total of 5 or less: Low-level of burnout

- Total between 6 and 11 inclusive: Moderate burnout

- Total of 12 and greater: High-level of burnout

Section C: Personal Achievement

The reduction of personal achievement: The individual assesses oneself negatively, feels he is unable to move the situation forward. This component represents the demotivating effects of a difficult, repetitive situation leading to failure despite efforts. The person begins to doubt his genuine abilities to accomplish things. This aspect is a consequence of the first two.

- Total of 33 or less: High-level of burnout

- Total between 34 and 39 inclusive: Moderate burnout

- Total greater than 40: Low-level of burnout

A high score in the first two sections and a low score in the last section may indicate burnout. The study included a total of 251 teachers from Bulgarian schools.
PROKOPOVIV., et al.

The study was conducted in the cities of Sofia, Blagoevgrad, Yambol, Kyustendil and Samokov.

The aim of the research is to study the burnout syndrome and the related psycho-physical and emotional state of the pedagogical specialists working in the system of school education.

The study will provide an opportunity to collect data on the severity of burnout, as well as the attitude of teachers to the problems of school education, leading to burnout. The study also involves collecting data on their attitudes to counteract the factors leading to burnout. The study also will provide a model for diagnosing burnout syndrome among teachers.

\section{RESULTS AND ANALYSIS}

The conducted survey allows an analysis of data on the age and gender characteristics of pedagogical specialists, their preliminary training in higher education and their professional realization. They are a starting point for analyzing empirical data.

Of the pedagogical specialists who participated in the study, $85 \%$ were women and $15 \%$ were men. This distribution of participants confirms a well-known but not very favorable trend in the teaching profession - its feminization.

In the age structure of the surveyed people more than half of the pedagogical specialists (54\%) are aged between 50 and 65 years, and almost equally (19 and 24\%) are distributed between 30-40 and 40-50 year-olds. Representatives of 25-30-year-olds are 3\%.

The data concerning the level of education show the high educational level, according to which Bulgarian teachers rank first in the European and world rankings on this indicator and once again confirm this lasting trend for Bulgarian education. Most teachers have a master's degree $-56 \%$, followed by those with a bachelor's degree $-36 \%$, only $2 \%$ have a lower education, "professional bachelor". One of the surveyed teachers has a PHD degree.

In connection with the professional experience of the participants it was established that the most numerous is the group of pedagogical specialists who have more than 15 years of pedagogical experience - 54\%, followed by those with 10 to 15 years of experience $(23 \%)$, between 5-10 years - 15\%, and the least 
PROKOPOV IV., et al.

number are teachers with up to 5 years of experience $(8 \%)$.

Figure 2 presents information on the study of module A concerning the emotional exhaustion. Emotional exhaustion is characterized by decreased emotional levels, indifference or emotional oversaturation, loss of interest in life. With low levels of emotional exhaustion, we found $17 \%$ of the teachers surveyed. Unfortunately, the highest level is of an extremely high level of emotionally exhausted teachers, namely - 37\%. The percentage of teachers with high levels of emotional exhaustion is relatively high - $23 \%$ and unfortunately only $2 \%$ of the respondents lack emotional exhaustion.

\section{Emotional exhaustion}

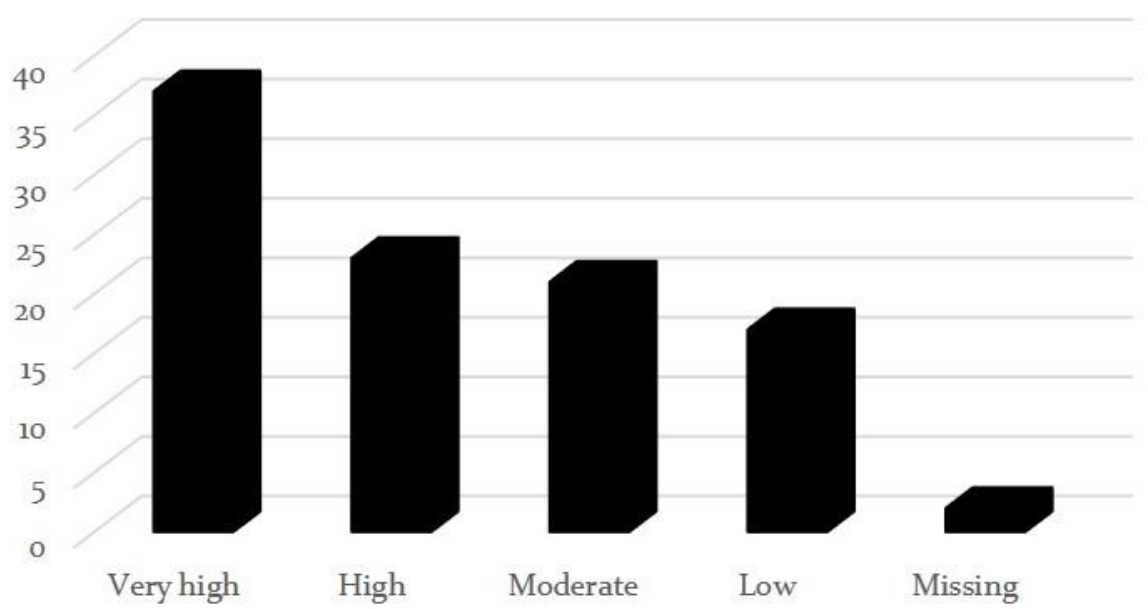

Figure 2. Degree of emotional exhaustion

Figure 3 presents data from modul B Depersonalization, which is associated with distortion in relationships with other people, opposition to those who contact them (parents, colleagues and relatives). The results of the teachers`survey are also disturbing in this direction. With extremely high levels of depersonalization are $35 \%$ of teachers, with high levels - 33\%, and with moderate - $21 \%$ the percentage of teachers who lack or have very low levels of depersonalization is respectively 3 and $8 \%$.

\section{Depersonalization}

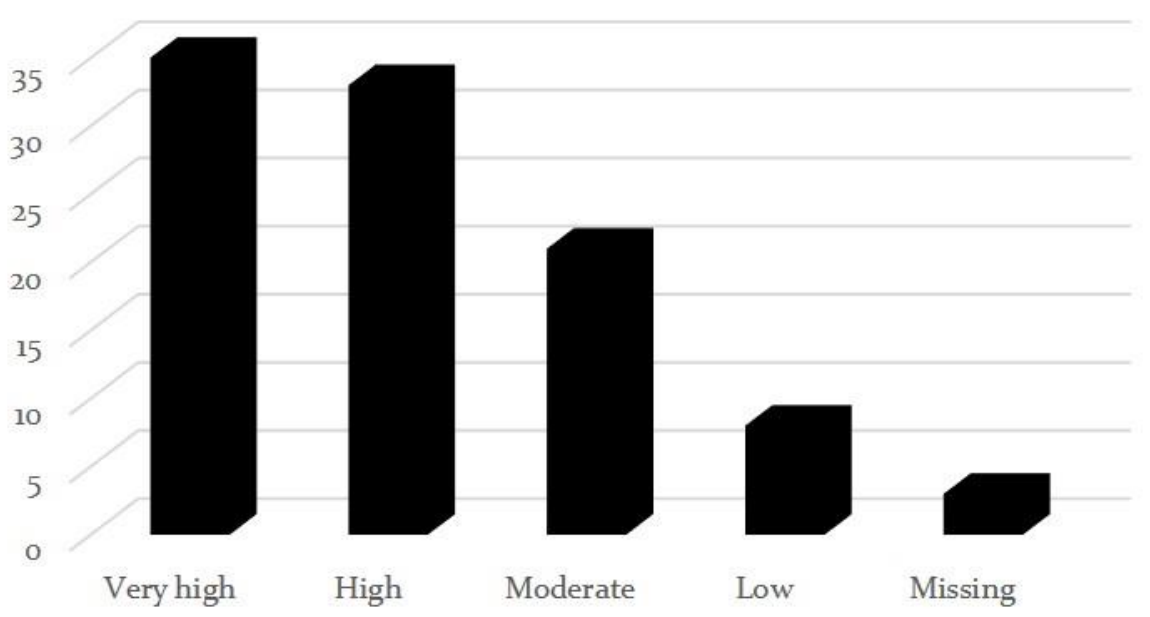

Figure 3. Degree of depersonalization

Figure 4 presents the distribution of the values of personal achievements. The results show that the highest percentage of $49 \%$ is of teachers with moderate personal achievement.
The extremely large percentage of surveyed teachers, $31 \%$ are with low levels of personal achievement, is also impressive. Only $17 \%$ of the respondents showed a high level of 
personal achievement. We attribute the obtained results to belittling the significance of our own achievements, lowering the self- esteem and professional motivation, and in some cases to a negative attitude on the part of the management of the educational institution.

\section{Personal achievements}

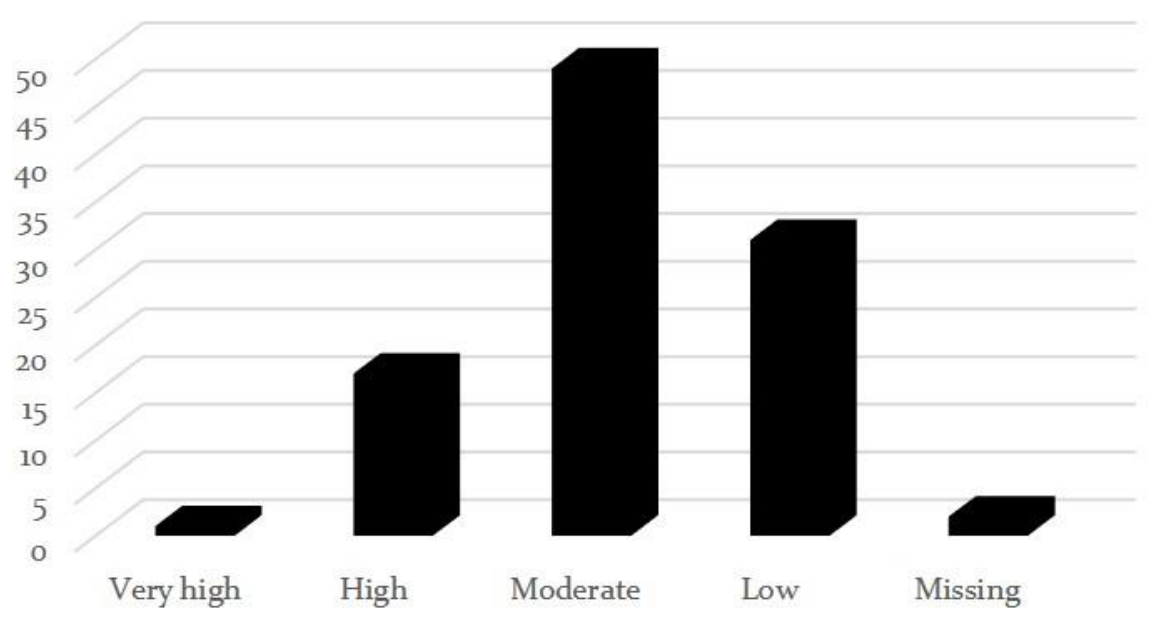

Figure 4. Degree of personal achievements

\section{CONCLUSIONS}

The following generalizations can be deduced from the analysis of the data obtained from the study of burnout syndrome among the pedagogical specialists. Burnout syndrome associated with stress has been documented in teachers. The reported high levels of emotional exhaustion (EE) in the subjects indicate significant emotional expenditure in the teaching profession. The increased degree of emotional exhaustion alienates the pedagogical specialists from both the students and the school as an institution and turns their pedagogical activity into a routine and unmotivated activity.

Despite the relatively high values of depersonalization (DP), teachers rarely develop a negative attitude towards themselves and others in the process of work and communication. For the most part, teachers have not changed their humanistic approach to students, and although they have been subjected to significant stress in their daily work, many of them have retained their philanthropy and empathy for students' problems. The data from the survey of indicators for the category of professional achievements (PA) of pedagogical specialists show that most of them have positive selfesteem for their pedagogical activity and the results of the educational process. However, there are many teachers who do not use their full professional potential as the main reasons can be found in the overload of organizational problems, the increased volume of documentation that they have to keep, and others.

To overcome the burnout syndrome in teachers, it is necessary for school authorities to implement targeted and systematic policy, including a set of activities, both personal and professional, so that those practicing this responsible socially important profession can realize the meaning of their professional activity and accept it as a source of pleasure and satisfaction.

\section{ACKNOWLEDGMENTS}

This article is published with the financial support of project №80-10-92/15.04.2020 Г.., according to Ordinance No. 9 of the State Budget of the Republic of Bulgaria.

\section{REFERENCES}

1. https://srzi.bg/bg/mejdunarodnaklasifikaciya-na-bolestite-10

2. OSH in figures: stress at work - facts and figures, European Agency for Safety and Health at Work - Luxembourg: Office for Official Publications of the European Communities 2009

3. Yanakieva, S. Emotional "burning" - one of the risks in the teaching profession. - icontinuing education, 2009, 15 and 17.

4. Freudenberger HJ. Staff burnout. Journal Soc. Issues, 1974; 30:13-18. 
5. Maslach C, Jackson S. The measurement of experienced burnout. J Occup Behav, 1981; 2:99-113.

6. Maslach C, Schaufeli W, Leiter M. Job burnout. Annu Rev Psychol, 2001; 52:397422

7. Lecheva Z., L. Georgieva, M. Stoycheva. Theoretical foundations of occupational stress and burnout syndrome. - Social Medicine, 2017, 1

8. Yanakieva, S., Satisfaction and mental health in the teaching profession, 130 years
PROKOPOV IV., et al. of preschool education in Bulgaria, edition: VTU, 2014

9. Zelenova M.E., Zakharov A.V. Burnout and stress in the context of military professional health. - Social psychology and society. 2014. Volume 5. No. 2. P. 50-70

10.Demina, L. D., I. A. Ralnikova. Mental health and protective mechanisms of personality. Altai, ASU, 2000.

11.Greenberg, J. Stress Management. St. Petersburg, Peter, 2004. 